\title{
Identification of valid housekeeping genes for quantitative RT-PCR analysis of cardiosphere-derived cells preconditioned under hypoxia or with prolyl-4-hydroxylase inhibitors
}

\author{
Suat Cheng Tan - Carolyn A. Carr • \\ Kar Kheng Yeoh • Christopher J. Schofield • \\ Kay E. Davies $\cdot$ Kieran Clarke
}

Received: 19 August 2011/Accepted: 24 October 2011/Published online: 9 November 2011

(C) The Author(s) 2011. This article is published with open access at Springerlink.com

\begin{abstract}
Infarction irreversibly damages the heart, with formation of an akinetic scar that may lead to heart failure. Endogenous cardiac stem cells (CSCs) are a promising candidate cell source for restoring lost tissue and thereby preventing heart failure. CSCs may be isolated in vitro, via the formation of cardiospheres, to give cardiospherederived cells (CDCs). Although qRT-PCR analyses of CDCs have been performed, no justification for the selection of the housekeeping gene has been published. Here, we evaluated the most suitable housekeeping gene for RNA expression analysis in CDCs cultured under normoxia, hypoxia or with prolyl-4-hydroxylase inhibitors (PHDIs), from both neonatal and adult rats, to determine
\end{abstract}

Electronic supplementary material The online version of this article (doi:10.1007/s11033-011-1281-5) contains supplementary material, which is available to authorized users.

S. C. Tan · C. A. Carr $(\varangle) \cdot$ K. E. Davies · K. Clarke Cardiac Metabolism Research Group, Department of Physiology, Anatomy \& Genetics, University of Oxford, Sherrington Building, Parks Road, Oxford OX1 3PT, UK

e-mail: carolyn.carr@dpag.ox.ac.uk

S. C. Tan

e-mail: suat.tan@dpag.ox.ac.uk

K. E. Davies

e-mail: kay.davies@dpag.ox.ac.uk

K. Clarke

e-mail: kieran.clarke@dpag.ox.ac.uk

K. K. Yeoh · C. J. Schofield

Department of Chemistry, University of Oxford, Chemistry Research Laboratory, Mansfield Road, Oxford OX1 3TA, UK

e-mail: karkheng.yeoh@chem.ox.ac.uk

C. J. Schofield

e-mail: christopher.schofield@ chem.ox.ac.uk the effects of ageing and different culture conditions on the stability of the housekeeping gene for CDCs. Six candidate housekeeping genes, [glyceraldehyde-3-phosphate dehydrogenase (GAPDH), beta-actin (Actb), hypoxanthine phosphoribosyltransferase 1 (HPRT-1), beta-2-microtubulin $(\beta 2 \mathrm{M}), 60 \mathrm{~S}$ acidic ribosomal protein large P1 (RPLP-1) and TATA box binding protein (Tbp)] were evaluated in this study. Analysis using geNorm and NormFinder revealed that GAPDH was the most constant housekeeping gene among all genes tested under normoxia for both neonatal and adult CDCs, whereas Actb was the most stable housekeeping gene under hypoxia. For the PHDItreated CDCs, overall, GADPH, Actb and $\beta 2 \mathrm{M}$ were more consistently expressed, whereas HPRT-1, RPLP-1 and Tbp showed unstable expression. The ranking for $\beta 2 \mathrm{M}$, HPRT-1 and RPLP-1 stability was different for neonatal and adult cells, indicating that expression of these genes was agedependent. Lastly, independent of age or culture conditions, Tbp was the least stable housekeeping gene. In conclusion, a combination of Actb and GADPH gave the most reliable normalization for comparative analyses of gene transcription in neonatal and adult rat CDCs preconditioned by hypoxia or PHDIs.

Keywords Housekeeping genes - Cardiosphere-derived cells · Hypoxia · Prolyl-4-hydroxylase inhibitors

\section{Introduction}

Stem cells were first identified within the heart in 2003 [1], challenging the generally accepted paradigm that the heart is a post mitotic organ [2, 3]. In 2004, Messina et al. [4] developed a method to isolate stem cells from human and murine heart, expanding them as cardiospheres (CSp). 
Such CSp were clonogenic, expressed stem and endothelial progenitor cell antigens/markers, and appeared to have the properties of adult cardiac stem cells. The CSp were expanded to obtain a reasonable number of cardiospherederived cells (CDC) for transplantation [5]. CSp and CDCs derived from heart explant culture in vitro caused myocardial regeneration and functional improvement when injected into the infarcted mouse heart in vivo $[4,5]$.

Preconditioning of stem cells to enable survival in the hypoxic environment has been postulated to improve cell production efficiency and potency for myocardial repair [6]. The implantation of hypoxic $\left(5 \% \mathrm{O}_{2}\right) \mathrm{CDCs}$ into infarcted hearts of mice in vivo resulted in greater cell engraftment and better functional recovery than with conventionally cultured (normoxic) CDCs [6]. Hypoxia triggers a number of physiological and cellular adaptations to reduced oxygen, with many processes involved in oxygen homeostasis being mediated by the hypoxia-inducible factor (HIF) transcriptional complex, which is negatively regulated by the prolyl-4-hydroxylase (PHD) enzyme. The PHD enzyme is a conserved subfamily of dioxygenases that uses oxygen and 2-oxoglutarate as a co-substrate and iron as a co-factor to catalyse the post-translational hydroxylation of specific prolyl residues of HIF- $\alpha$ subunits [7-9]. Upon hydroxylation, the HIF- $1 \alpha$ subunit is recognized by the von Hippel-Lindau protein which targets the subunit to proteasomal degradation [9]. The sensitivity of PHD hydroxylase capacity depends on its co-substrate and co-factor. Thus, limited oxygen supply or inhibition of the 2-oxoglutarate or iron could inhibit PHD activity and thus potently activate the HIF response [10-13].

Here, we cultured CDCs under hypoxia (2\% oxygen) or used three different prolyl-4-hydroxylase inhibitors (PHDIs) for CDC HIF stabilization. The PHDIs used in this study included dimethyloxaloylglycine (DMOG) - a cell permeable, competitive inhibitor of 2-oxoglutarate [11], ethyl 2-(2,3-dihydroxybenzamido) acetate (EDBA) - an aspirin metabolite that activates the HIF system via generic 2-oxoglutarate oxygenase inhibition [14], and 2-(1-chloro4-hydroxyisoquinoline-3-carboxamido) acetic acid (BIC) a specific PHD inhibitor patented by FibroGen Inc. (FG2216), which has been used in clinical trials as a proangiogenic compound acting via the HIF- $1 \alpha$ system [12].

Gene expression analyses are useful to investigate changes in the CDC phenotype after hypoxic and PHDI treatment. The most commonly used technique for gene expression analysis is quantitative (real-time) reverse transcriptase polymerase chain reaction (qRT-PCR), in which expression magnitude is normalized to a reference gene. This gene, referred to as a housekeeping gene, is typically a constitutive gene that is expressed at relatively constant levels in all cells independent of experimental conditions. Selection of the housekeeping gene is crucial because it directly influences the interpretation of qRTPCR data. However, no one housekeeping gene is universal under all experimental conditions. Many papers have been published using qRT-PCR analysis of CDCs [15-17], hypoxic CDCs [6] or other cells treated with PHDIs [1821], but none have described the background for selecting a suitable housekeeping gene for quantification. Therefore, in this study, we evaluated the most suitable housekeeping gene for RNA expression analysis in normoxic, hypoxic and PHDI-preconditioned CDCs isolated from both neonatal and adult rat hearts, using a panel of 6 housekeeping genes, glyceraldehyde-3-phosphate dehydrogenase (GAP$\mathrm{DH}$ ), beta-actin (Actb), hypoxanthine phosphoribosyltransferase 1 (HPRT-1), beta-2-microtubulin $(\beta 2 \mathrm{M}), 60 \mathrm{~S}$ acidic ribosomal protein large P1 (RPLP-1) and TATA box binding protein (Tbp) (Table 1). These genes were chosen as they are most commonly used as reference genes in rat qRT-PCR studies [16, 22-32] (Additional file 1).

\section{Results}

\section{Hypoxic response}

Western blot analysis showed that CDCs cultured under hypoxia or treated with PHDIs had significantly increased HIF- $1 \alpha$ protein levels, compared to normoxic CDCs (Fig. 1). This indicated that the hypoxic challenge to the cells and the PHDI treatments successfully elevated HIF- $1 \alpha$.

\section{RNA and cDNA quality}

RNA was isolated from neonatal and adult CDCs subjected to five different culture conditions (Table 2). The RNA purity was measured using a NanoDrop ${ }^{\circledR}$ Spectrophotometer (NanoDrop Technologies). On average, the $\mathrm{A}_{260 / 280}$ ratio of RNA samples was $2.01 \pm 0.04$, indicating protein-free pure RNA, and the ratio of $\mathrm{A}_{260 / 230}$ was $1.98 \pm 0.21$, indicating that the RNA was phenol and ethanol free. cDNA was synthesized from the pure RNA template and cDNA purity was verified with the mean ratio of $\mathrm{A}_{260 / 280}=1.81 \pm 0.01$.

\section{Primer efficiency}

Primers for GAPDH, Actb, HPRT-1, $\beta 2 \mathrm{M}$, RPLP-1, Tbp and HIF- $1 \alpha$ were designed using Primer 3 software. A primer efficiency test using serial dilution curves gave efficiencies for all primers from 92 to $99 \%$ with a correlation coefficient $\left(\mathrm{R}^{2}\right)$ ranging from 0.92 to 0.99 (Table 3), indicating that all the designed primers worked successfully and gave consistent results throughout efficiency testing. 


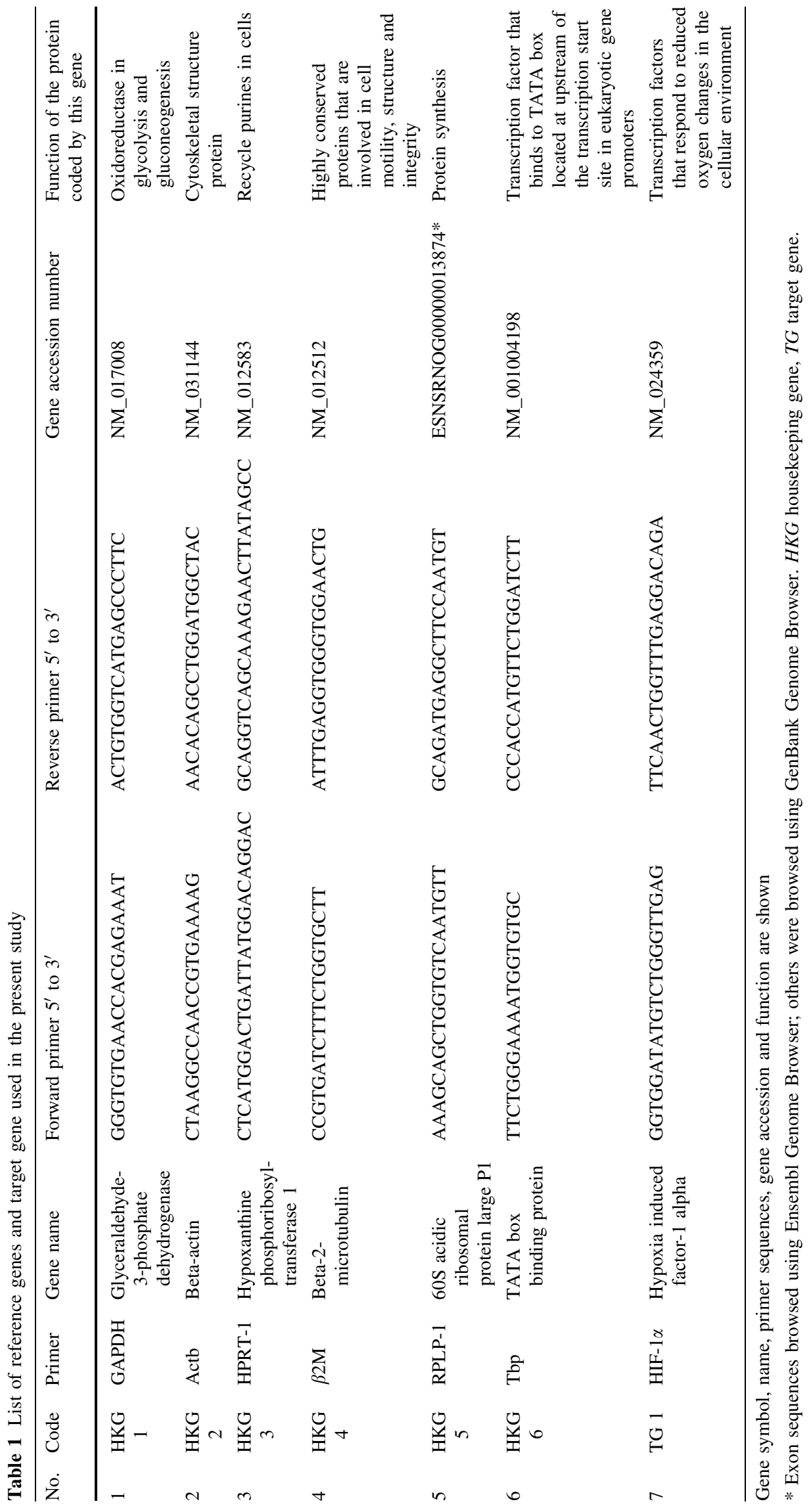


Fig. 1 Western blot analysis of HIF- $1 \alpha$ protein levels in neonatal and adult P2 CDCs cultured under hypoxia or with DMOG, EDBA and BIC. In each group, all values were normalized to levels in normoxic CDCs (control). Culture under hypoxia or with PHDIs increased expression of HIF- $1 \alpha . * P<0.05$ vs. control, $n=3$

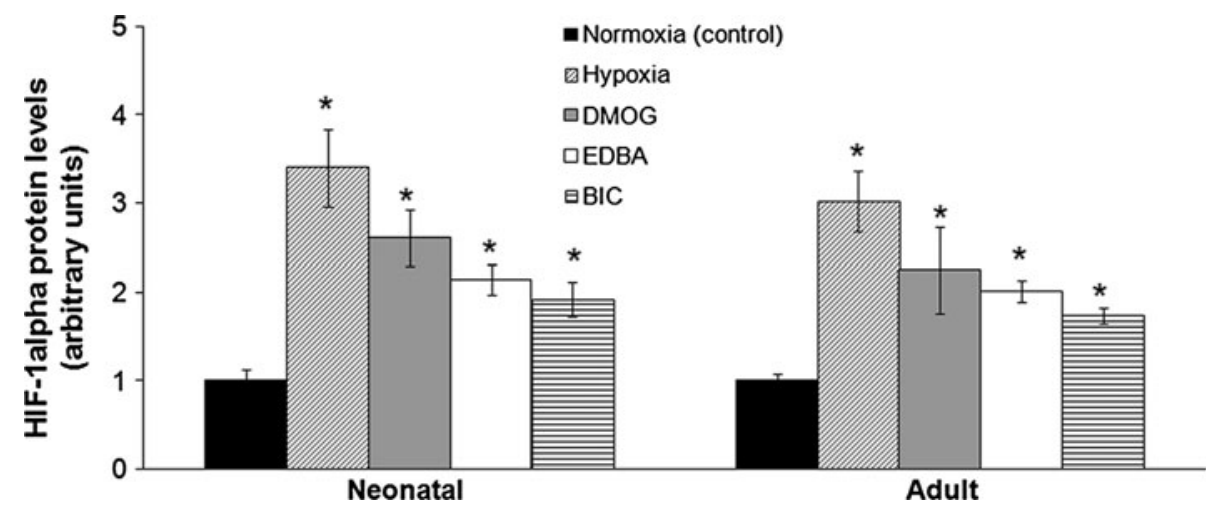

Table 2 CDC sample groups

\begin{tabular}{|c|c|}
\hline Age of animals & Culture conditions \\
\hline (a) Neonatal (1-3 days) & (i) Normoxia $\left(21 \% \mathrm{O}_{2}\right)$ (control) \\
\hline \multirow[t]{4}{*}{ (b) Adult (4 months) } & (ii) Hypoxia $\left(2 \% \mathrm{O}_{2}\right)$ \\
\hline & (iii) Normoxia $+1 \mathrm{mM}$ DMOG for $24 \mathrm{~h}$ \\
\hline & (iv) Normoxia $+0.5 \mathrm{mM}$ EDBA for $24 \mathrm{~h}$ \\
\hline & (v) Normoxia $+30 \mu \mathrm{M}$ BIC for $24 \mathrm{~h}$ \\
\hline
\end{tabular}

CDCs were cultured from (a) neonatal and (b) adult rat hearts. CDCs from each group were subjected to five different culture conditions (i)-(v)

$D M O G$ dimethyloxalyl glycine, EDBA Ethyl 2-(2,3-dihydroxybenzamido) acetate, BIC 2-(1-chloro-4-hydroxyisoquinoline-3-carboxamido) acetic acid

Table 3 List of reference genes and target gene used in the present study

\begin{tabular}{lll}
\hline Gene name & Primer efficiency & Correlation coefficient $\left(\mathrm{R}^{2}\right)$ \\
\hline GAPDH & 99.3 & 0.99 \\
$\beta 2 \mathrm{M}$ & 91.6 & 0.97 \\
HPRT-1 & 92.3 & 0.99 \\
Actb & 92.7 & 0.99 \\
RPLP-1 & 94.9 & 0.92 \\
Tbp & 93.8 & 0.93 \\
HIF- $1 \alpha$ & 98.2 & 0.92
\end{tabular}

Gene name, primer efficiency and the correlation coefficient are shown

The expression profiles of candidate housekeeping genes

qRT-PCR was performed and the cycle threshold $(\mathrm{Ct})$ values were plotted directly, assuming the same threshold for all genes. Ct is defined as the number of cycles needed for fluorescence to reach a specific threshold level of detection and is inversely related to the amount of initial RNA template present in the sample. The six candidate housekeeping genes showed a wide $\mathrm{Ct}$ expression range, with values

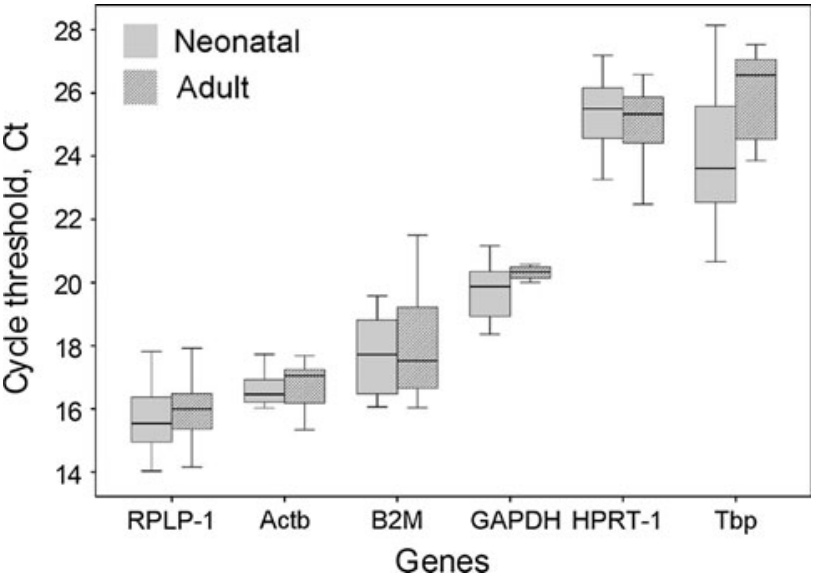

Fig. 2 Expression levels of candidate housekeeping genes in normoxic, hypoxic and PHDI-treated CDCs cultured from neonatal and adult rat hearts. Boxes represents lower and upper quartiles of cycle thresholds range with the median indicated, whiskers represent the 10th and 90th percentiles. Grey boxes correspond to neonatal CDCs and hatched boxes correspond to adult CDCs. In both groups, RPLP-1 was the most highly expressed gene (least $\mathrm{Ct}$ value), followed by Actb, $\beta 2 \mathrm{M}$, GAPDH and lastly the HPRT-1 and Tbp as the least expressed genes (highest $\mathrm{Ct}$ values)

between 14 and 28 cycles (Fig. 2). These genes had different expression levels, with RPLP-1 being the most abundantly expressed gene, presenting average $\mathrm{Ct}$ values below 16 cycles. Actb, $\beta 2 \mathrm{M}$ and GAPDH were moderately expressed in these samples, with average $\mathrm{Ct}$ values between 16 and 22 cycles, while Tbp and HPRT- 1 were the least expressed housekeeping genes, with $\mathrm{Ct}$ values above 24 cycles. For qRT-PCR normalization, a moderately expressed housekeeping gene is preferred because extremely high or low expression of a housekeeping gene could introduce variability to the data analysis.

\section{HKGs stability test using geNorm and Normfinder}

To identify the housekeeping gene with the most stable expression in the CDC samples, two software-based methods were used: geNorm and NormFinder. 


\section{geNorm analysis}

geNorm is a well published Microsoft Excel based program designed to validate stability of housekeeping gene expression. The underlying principles and calculations are described in Vandesompele et al. [33]. In brief, geNorm ranks gene stability by an average expression stability value $(\mathrm{M})$, which is the average pairwise variation of a single candidate housekeeping gene with all other candidate housekeeping genes. More stable gene expression is indicated by lower $\mathrm{M}$ values.

To investigate the effects of ageing on the ranking of candidate genes, housekeeping gene stability was determined in neonatal and adult CDCs (Fig. 3a, b). In the neonatal cells, both Actb and GAPDH genes had the lowest M value, followed by RPLP-1, $\beta 2 \mathrm{M}$, HPRT-1 and Tbp. This indicated that in neonatal CDCs preconditioned with either hypoxia or PHDI, Actb and GAPDH were most stable genes and Tbp was the least stable gene (Fig. 3a). In the adult cells, a combination of Actb and GAPDH genes was found to be the most stable housekeeping genes, compared to other candidate genes. However, the ranking for $\beta 2 \mathrm{M}$, HPRT-1 and RPLP-1 was different from that found in the neonatal group (Fig. 3b), indicating that expression of $\beta 2 \mathrm{M}$, HPRT-1 and RPLP-1 was age-dependent. Independent of age, Tbp was the least stable housekeeping gene. When neonatal and adult CDCs were analyzed in combination, a similar ranking of candidate genes was observed (Fig. 3c).

In addition, geNorm analysis revealed the optimal number of housekeeping genes required for reliable and accurate normalization of qRT-PCR expression data, based on the average pairwise variation $V_{n} / V_{n+1}$ calculated between $n$ and $n+1$ housekeeping genes (recommended cut-off threshold of $\mathrm{V}_{\mathrm{n}} / \mathrm{V}_{\mathrm{n}+1}=0.15$ ) [33]. In both neonatal and adult groups, the pairwise variation $\mathrm{V}_{2 / 3}<0.15$ indicated there was no need to include a third gene to calculate the normalization factor. Therefore, the two best performing housekeeping genes, GAPDH and Actb, could accurately normalize qRT-PCR expression (Fig. 4).

However, a limitation of this software is that the $\mathrm{M}$ value measured is the expression of a single gene as a ratio of the other genes tested. Thus, we could not resolve the best gene out of the two best performing genes, GADPH and Actb. In addition, geNorm analysis relies on the principle that the two best performing genes are identical in all samples, regardless of the experimental conditions or treatments, which is not necessarily true. To address this problem, NormFinder software was also used.

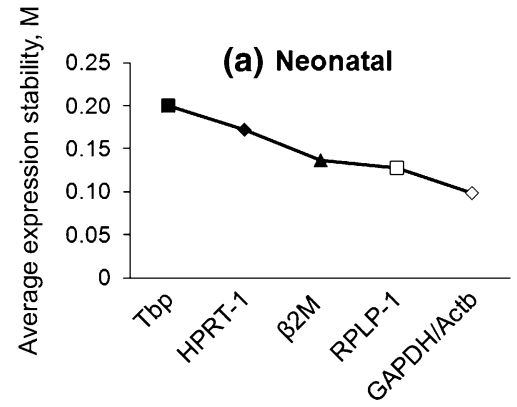

Fig. 3 geNorm analysis of the candidate housekeeping genes average expression stability, M. Genes with highest $M$ value represents the least stable gene. Samples were analyzed separately according to the
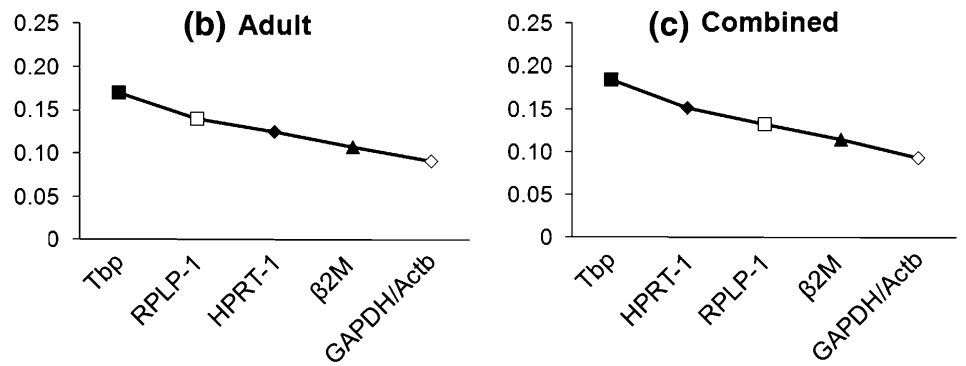

age group. a neonatal. $\mathbf{b}$ adult or $\mathbf{c}$ were analyzed in a combined set (results obtained from three sets of biological replicates)

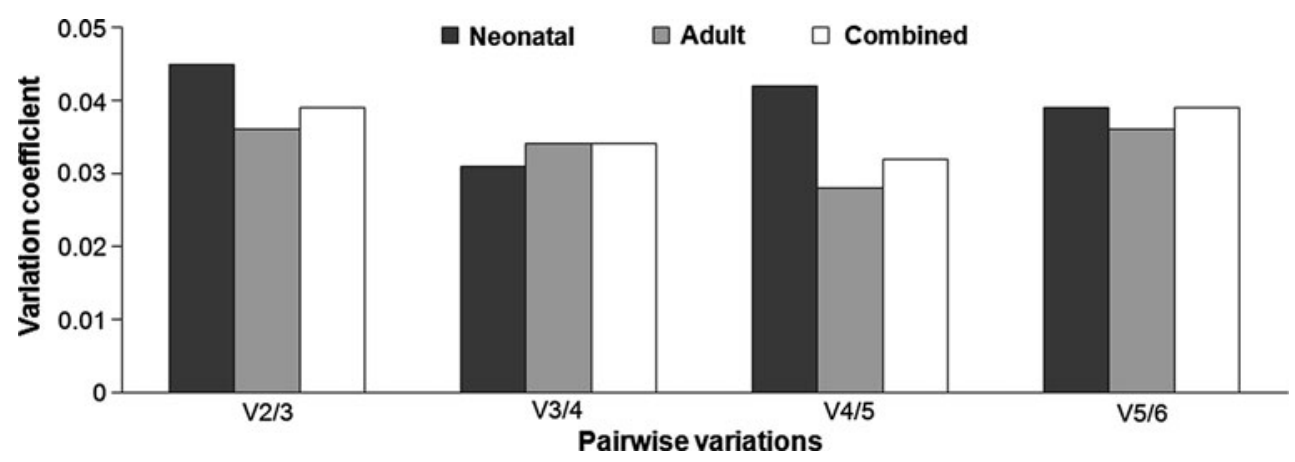

Fig. 4 geNorm analysis of the optimal number of housekeeping genes required for data normalization. A variation coefficient, V, value below 0.15 was accepted as indicating the optimal number of genes required for the data normalization. V2/3 $<0.15$ indicated that 2 genes were required for the data normalization (results obtained from three sets of biological replicates) 


\section{NormFinder analysis}

NormFinder, introduced by Andersen et al. [34], assesses the expression stability of a gene by evaluating the variation of expression within groups or between groups. Genes with the lowest variation values (V) have the most stable expression and are therefore ideal reference genes. This program allows not only the estimation of overall expression variation of the candidate housekeeping genes across a group of samples, but also of the variation between subgroups of a sample, e.g., normoxic CDCs versus hypoxic CDCs or non-treated CDCs versus PHDI-treated CDCs. Using NormFinder, we found that GADPH was the most stable gene expressed in both neonatal and adult normoxic cells, while Actb was the most stable gene expressed in both neonatal and adult hypoxic cell groups. For DMOG and EDBA-treated samples, GADPH was the best housekeeping gene for neonatal cells and Actb was best for adult cells. For BIC-treated samples, GADPH was the best housekeeping gene for neonatal cells and $\beta 2 \mathrm{M}$ was the best for adult cells (Table 4a, b). Overall, GADPH, Actb and $\beta 2 \mathrm{M}$ were the most consistently expressed housekeeping genes, always ranked in the first three places, while HPRT1, RPLP-1 and Tbp were unstable, ranked in the last three places (Table 4c). Intergroup stability showed that a combination of GAPDH and Actb were the best housekeeping genes (Fig. 5) (Additional information as given in Additional file 2).

HIF- $1 \alpha$ mRNA expression normalized by different HKGs

We used normalization to different housekeeping genes to compare the gene expression of HIF- $1 \alpha$ in CDCs preconditioned under normoxia or hypoxia or with PHDIs, for CDCs from both neonatal and adult rat hearts. Normalization was performed using GAPDH, Actb, HPRT-1, RPLP-1, $\beta 2 \mathrm{M}$, Tbp and a combination of GAPDH and Actb as reference genes. As shown in Fig. 6, when expression levels were normalized to the non-stable housekeeping genes, HPRT-1, RPLP-1 or Tbp, HIF- $1 \alpha$ expression was the same for the normoxic, hypoxic and PHDI-treated samples for either neonatal or adult groups. Normalization to GADPH, Actb or $\beta 2 \mathrm{M}$ gave significantly different results in some, but not all, samples. All hypoxic and PHDI-treated samples from both neonatal and adult groups showed significant increases in HIF- $1 \alpha$ expression, compared with the normoxic control, only when the qRT-PCR data were normalized to the combination of GAPDH and Actb, the optimal HKGs combination validated using geNorm and NormFinder, demonstrating that the simultaneous use of two optimal housekeeping genes (GAPDH and Actb) is required to generate valid normalized qRT-PCR data.

\section{Discussion}

This study clearly illustrates the differences in stability of housekeeping genes in rat CDCs cultured under normoxia $\left(21 \% \mathrm{O}_{2}\right)$, hypoxia $\left(2 \% \mathrm{O}_{2}\right)$ or with the PHDIs: DMOG, EDBA or BIC.

Preconditioning of cells under hypoxia or in the presence of an iron chelator (EDBA), a 2-oxoglutarate analogue (DMOG) or a specific prolyl hydroxylation inhibitor (BIC), inhibits PHD enzyme activity and subsequently activates the HIF transcriptional complex [10-13]. Analysis of protein levels in hypoxic and PHDI-treated CDCs revealed a significant increase in HIF- $\alpha$ expression, compared to normoxic $\mathrm{CDCs}$, in both the neonatal and adult group, indicating that the hypoxic challenge to the cells was successful. Analysis of mRNA levels in hypoxic and PHDI-treated CDCs using qRT-PCR is, however, not as straightforward as the protein analysis. The analysis of qRT-PCR data required normalization using a consistently expressed housekeeping gene.

RPLP-1, which plays a role in the elongation step of protein synthesis [35], was the most abundantly expressed gene in the rat CDCs, whereas HPRT-1 (an enzyme which recycles purine in cells) [36] and Tbp (a transcription factor which binds to the TATA-box DNA sequence) [37], were the least expressed genes. Genes with extensive or low expression are not suitable reference genes for qRT-PCR due to their extreme transcription expression. Our conclusions were validated by the geNorm and Normfinder analysis, which showed that these three genes were relatively unstable, compared to GAPDH, $\beta 2 \mathrm{M}$ and Actb, which showed moderate expression in rat CDC.

To evaluate the effect of ageing on HKG stability, we grouped the samples into neonatal and adult groups and analyzed the data either separately or as a combined set using geNorm. In both approaches, we found that a combination of GAPDH and Actb were best to be used as housekeeping gene, while the Tbp was the least stable among all the candidate genes. The instability of $\beta 2 \mathrm{M}$, HPRT-1 and RPLP-1 at different stages of heart development is a drawback in their use as housekeeping genes.

Normalization with multiple reference genes is becoming more prevalent, but studies that apply this normalization approach are limited. Based on geNorm analysis, we found that an optimum of two housekeeping genes was needed to perform a valid normalization. To confirm this, we evaluated the expression of HIF- $1 \alpha$ mRNA in the study samples normalized to only one housekeeping gene or to a combination of the two best housekeeping genes as selected by geNorm analysis. Interestingly, only the data set normalized to the geometric mean of GADPH and Actb genes showed a significant increase in HIF- $1 \alpha$ expression in every sample. Thus, two housekeeping genes seemed optimal for accurate normalization in this study. 
Table 4 Ranking of candidate HKGs and their expression stability, V in the different sample groups of the study evaluated using NormFinder

\begin{tabular}{|c|c|c|c|c|c|c|c|c|c|}
\hline \multicolumn{2}{|c|}{ Normoxia } & \multicolumn{2}{|l|}{ Hypoxia } & \multicolumn{2}{|c|}{ DMOG $1 \mathrm{mM}$} & \multicolumn{2}{|c|}{ EDBA $0.5 \mathrm{mM}$} & \multicolumn{2}{|c|}{ BIC $30 \mu \mathrm{M}$} \\
\hline Ranking & $\begin{array}{l}\text { Stability } \\
\text { value }\end{array}$ & Ranking & $\begin{array}{l}\text { Stability } \\
\text { value }\end{array}$ & Ranking & $\begin{array}{l}\text { Stability } \\
\text { value }\end{array}$ & Ranking & $\begin{array}{l}\text { Stability } \\
\text { value }\end{array}$ & Ranking & $\begin{array}{l}\text { Stability } \\
\text { value }\end{array}$ \\
\hline
\end{tabular}

(a) Neonatal CDCs

\begin{tabular}{|c|c|c|c|c|c|c|c|c|c|}
\hline 1) $G A P D H$ & 0.053 & 1) Actb & 0.139 & 1) $G A P D H$ & 0.087 & 1) $G A P D H$ & 0.051 & 1) $G A P D H$ & 0.092 \\
\hline 2) Actb & 0.113 & 2) $G A P D H$ & 0.160 & 2) $A c t b$ & 0.362 & 2) $A c t b$ & 0.121 & 2) Actb & 0.192 \\
\hline 3) $\beta 2 M$ & 0.158 & 3) $\beta 2 M$ & 0.189 & 3) $\beta 2 M$ & 2.224 & 3) $\beta 2 M$ & 0.152 & 3) $\beta 2 M$ & 0.591 \\
\hline 4) $R P L P-1$ & 4.606 & 4) $T b p$ & 1.910 & 4) $H P R T-1$ & 3.215 & 4) $H P R T-1$ & 2.951 & 4) $R P L P-1$ & 1.757 \\
\hline 5) $T b p$ & 14.744 & 5) $R P L P-1$ & 3.068 & 5) $R P L P-1$ & 4.935 & 5) $R P L P-1$ & 5.014 & 5) $H P R T-1$ & 3.055 \\
\hline 6) $H P R T-1$ & 15.586 & 6) $H P R T-1$ & 17.241 & 6) $\mathrm{Tbp}$ & 20.389 & 6) $\mathrm{Tbp}$ & 11.328 & 6) $T b p$ & 14.794 \\
\hline \multicolumn{10}{|c|}{ (b) Adult CDCs } \\
\hline 1) $G A P D H$ & 0.233 & 1)Actb & 0.200 & 1) $A c t b$ & 0.216 & 1) $A c t b$ & 0.333 & 1) $\beta 2 M$ & 0.040 \\
\hline 2) Actb & 0.747 & 2) $\beta 2 M$ & 0.388 & 2) $G A P D H$ & 0.414 & 2) $G A P D H$ & 0.447 & 2) $A c t b$ & 0.156 \\
\hline 3) $\beta 2 M$ & 1.077 & 3) $G A P D H$ & 0.419 & 3) $\beta 2 M$ & 1.498 & 3) $\beta 2 M$ & 0.542 & 3) $G A P D H$ & 0.275 \\
\hline 4) $R P L P-1$ & 2.502 & 4) $R P L P-1$ & 4.592 & 4) $H P R T-1$ & 4.380 & 4) $T b p$ & 1.482 & 4) $R P L P-1$ & 1.495 \\
\hline 5) $H P R T-1$ & 10.524 & 5) $H P R T-1$ & 8.784 & 5) $R P L P-1$ & 4.682 & 5) $R P L P-1$ & 2.106 & 5) $T b p$ & 1.608 \\
\hline 6) $T b p$ & 13.181 & 6) $\mathrm{Tbp}$ & 15.939 & 6) $T b p$ & 6.490 & 6) $H P R T-1$ & 10.410 & 6) $H P R T-1$ & 3.381 \\
\hline \multicolumn{10}{|c|}{ (c) Combined (neonatal and adult CDCs) } \\
\hline 1) $G A P D H$ & 0.002 & 1) $G A P D H$ & 0.315 & 1) $A c t b$ & 0.359 & 1) $A c t b$ & 0.263 & 1) $\beta 2 M$ & 0.072 \\
\hline 2) $A c t b$ & 0.161 & 2) $A c t b$ & 1.059 & 2) $G A P D H$ & 1.215 & 2) $\beta 2 M$ & 0.718 & 2) Actb & 0.248 \\
\hline 3) $\beta 2 M$ & 0.298 & 3) $\beta 2 M$ & 1.793 & 3) $\beta 2 M$ & 2.201 & 3) $G A P D H$ & 1.491 & 3) $G A P D H$ & 1.105 \\
\hline 4) $R P L P-1$ & 3.981 & 4) $R P L P-1$ & 2.188 & 4) $H P R T-1$ & 3.160 & 4) $R P L P-1$ & 2.519 & 4) $R P L P-1$ & 1.263 \\
\hline 5) $H P R T-1$ & 12.482 & 5) $\mathrm{Tbp}$ & 4.208 & 5) $R P L P-1$ & 3.844 & 5) $T b p$ & 4.834 & 5) $H P R T-1$ & 2.520 \\
\hline 6) $T b p$ & 25.530 & 6) $H P R T-1$ & 6.658 & 6) $T b p$ & 16.492 & 6) $H P R T-1$ & 6.447 & 6) $T b p$ & 9.298 \\
\hline
\end{tabular}

Bold type indicates the reference genes that were consistently ranked the top places, and thus can be categorized as stable HKGs in this study as compared to other three candidate genes

Samples were analyzed separately according to age group, (a) neonatal and (b) adult or were analyzed in a (c) combined set of neonatal and adult. Gene with the lowest stability value has the most stable expression. Stability values are listed from most stable to least stable

In our experiments, the sample sets included different stages of heart development (neonatal versus adult rat hearts), different oxygen tensions (normoxic versus hypoxic) and three different PHDI drug treatments (DMOG, EDBA or BIC). For NormFinder analysis, we grouped the samples within each experiment, taking into account the genes associated with cardiac progenitor cells in normoxic and hypoxic CDCs or between physiologically-induced hypoxia using hypoxic culture and pharmaceuticallyinduced hypoxia using PHDIs. We found that GADPH was the most stable gene expressed in the normoxic cell group. However, the expression of this gene was unstable in hypoxic CDCs where Actb was the most stable gene expressed. For the PHDI-treated samples, there were different best housekeeping genes selected for each inhibitor, yet overall, GADPH, Actb and $\beta 2 \mathrm{M}$ were the most stable reference genes. Although different housekeeping genes were selected for the different experimental conditions, when the stability of housekeeping genes were considered over all groups, the best housekeeping genes revealed by NormFinder analysis was GADPH and Actb combined.

\section{Conclusions}

In conclusion, both geNorm and NormFinder analysis revealed that GAPDH and Actb were the best housekeeping genes for this study. geNorm also indicated that two housekeeping genes were required for valid qRT-PCR data normalization. In most cases, using multiple housekeeping genes resulted in more accurate and reliable normalization compared with the use of only one reference gene. Thus, we suggest that Actb and GADPH genes should be both used as the housekeeping genes in qRT-PCR involving normoxia, hypoxic and PHDI-treated neonatal and adult rat CDCs.

\section{Methods}

Animals

Sprague-Dawley (SD) rats were used for all experiments. All experiments were performed with approval from The 
Fig. 5 NormFinder analysis of the candidate housekeeping genes average stability values (V). Genes with highest V value represent the least stable gene (results obtained from three sets of biological replicates)
Fig. 6 Expression level of HIF- $1 \alpha$ mRNA in a neonatal and $\mathbf{b}$ adult CDCs upon normalization to different housekeeping gene. All data are relative to the normoxic sample (control). Normalization to the best combination of GAPDH/ Actb validated by geNorm and NormFinder showed significantly increased expression of HIF- $1 \alpha$ mRNA in both neonatal and adult groups under all experimental conditions. $* P<0.05$, ${ }^{\#} P<0.01$
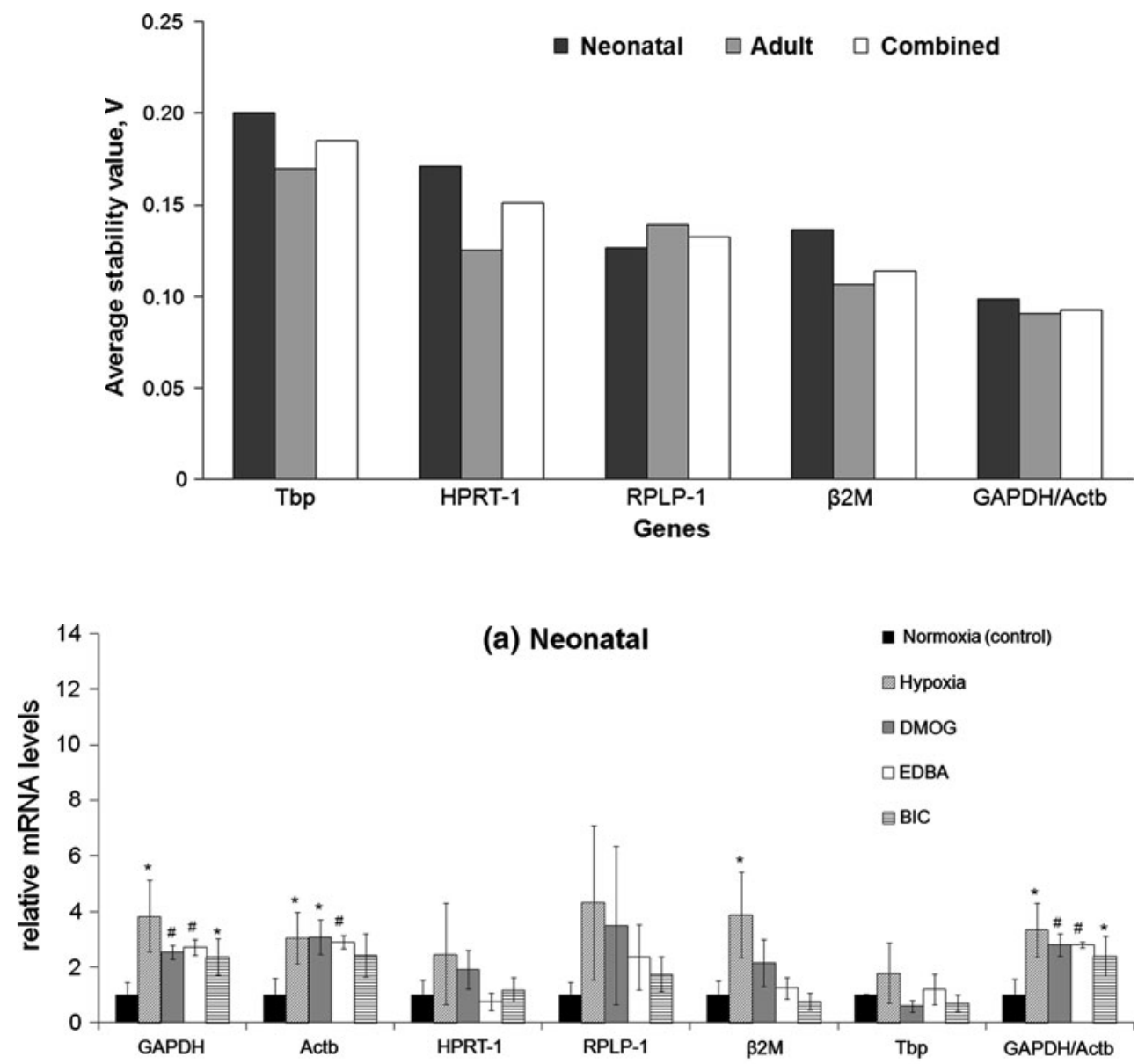

(b) Adult

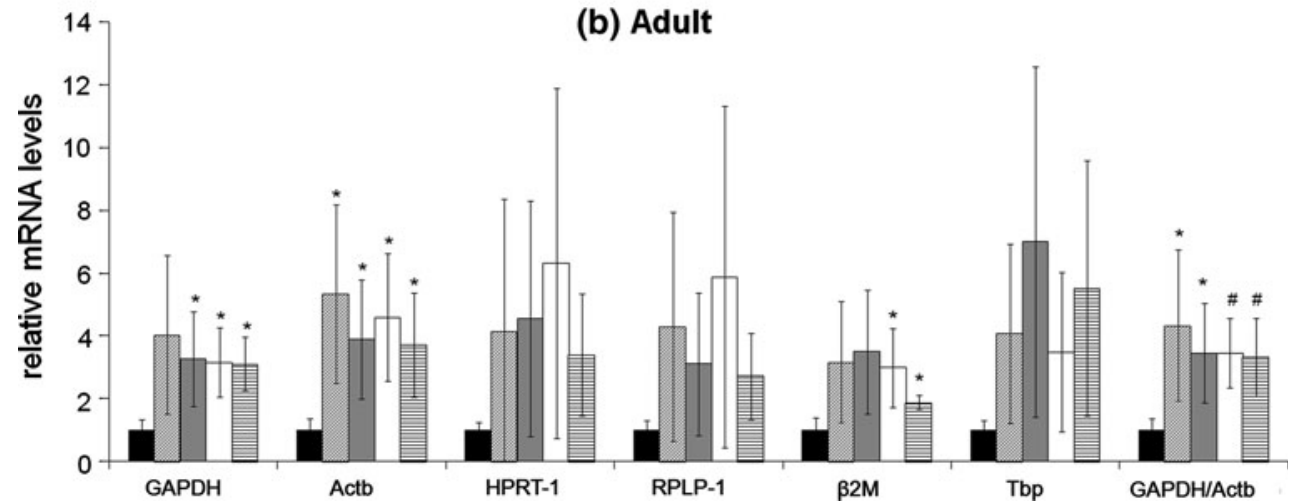

University of Oxford Animal Ethics Review Committees and the Home Office (London, UK).

Primary cardiac stem cell culture

CDCs were isolated and expanded according to a protocol described previously [5]. In brief, neonatal (1-3 days) and adult (4 months) SD rat hearts were isolated, and minced into small explants in $0.05 \%$ trypsin-EDTA (Invitrogen). Explants were plated on fibronectin-coated petri dishes with
$1.5 \mathrm{ml}$ of complete explant medium (CEM, Additional file 3) to generate explant-derived cells (EDCs). EDC, once confluent, were isolated and seeded onto poly-D-lysine coated 24-well plates with cardiosphere growth medium (CGM, Additional file 3) to form spherical cell clusters, known as Csp. Loosely attached Csp were harvested and plated onto fibronectin-coated T75 flasks with CEM, at a density of $1 \times 10^{4}$ cells/flask for expansion into cardiosphere derived cells (CDCs). All the cells were cultured in incubator under $21 \% \mathrm{O}_{2}$ and $5 \% \mathrm{CO}_{2}$, at $37^{\circ} \mathrm{C}$, unless otherwise stated. 
CDC preconditioned with hypoxia and PHDIs

For hypoxic-preconditioned cells, CDCs were cultured under $2 \% \quad \mathrm{O}_{2}$ (hypoxia) and $5 \% \quad \mathrm{CO}_{2}$ at $37^{\circ} \mathrm{C}$ using an incubator (Wolf Laboratories, UK) adjustable to different oxygen concentrations by infusion of nitrogen $\left(\mathrm{N}_{2}\right)$. The $\mathrm{O}_{2}$ concentration was monitored continuously using an $\mathrm{O}_{2}$ sensor. For PHDI-preconditioning, normoxic CDCs (cultured under $21 \% \mathrm{O}_{2}$ and $5 \% \mathrm{CO}_{2}$, at $37^{\circ} \mathrm{C}$ ) were treated with $1 \mathrm{mM}$ of DMOG, $0.5 \mathrm{mM}$ of EDBA or $30 \mu \mathrm{M}$ of BIC for $24 \mathrm{~h}$ at $80 \%$ cell confluency.

\section{Western blot analysis for HIF- $1 \alpha$ protein}

Normoxic, hypoxic and PHDI-preconditioned CDCs were lysed in cell lysis buffer containing protease inhibitor. The homogenate was boiled and centrifuged for $5 \mathrm{~min}$, the supernatant frozen and stored at $-80^{\circ} \mathrm{C}$. The lysate $(50 \mu \mathrm{g} / \mu \mathrm{l})$ was subjected to SDS-polyacrylamide gel (10\%) electrophoresis, and protein was subsequently transferred to a nitrocellulose membrane (Pall Life Science, Mexico). The membrane was incubated overnight with rat HIF- $1 \alpha$ primary antibody diluted (1:2000) in 5\% milk in TBS-Tween (Novus, NB100-479). The secondary antibody used was goat anti-rabbit conjugated to horseradish peroxidase (1:2000) (Santa Cruz Biotechnology, Santa Cruz, CA). The immunoreactive protein signal was visualized by an ECL plus detection kit (Perkin Elmer). Protein bands were quantified using Un-Scan-It, Version 6.1 (Silk Scientific, USA).

\section{Primer design and optimization}

Primers were designed using Primer3 software based on interpretation of GenBank or Ensembl Genome Browser search results (Table 2). Primer specificity was enhanced by designing a primer pair that flanked the exon-exon border of the gene of interest, to avoid the primers amplifying genomic DNA that may be contained in samples. Primer specificity was confirmed by blasting the primer sequence against genomic databases available at NCBI. No significant homology sequence should be found, to ensure gene specific amplification rather than amplification of several transcripts with one primer pair.

RNA extraction and DNase treatment

Total RNA was extracted from cultured CDCs using Trizol reagent (Sigma) according to the manufacturer's instructions. DNase treatment was performed using Turbo DNAfree (Ambion) to degrade any DNA present. The concentration and purity of RNA was determined by measuring the absorbance at $260 \mathrm{~nm}$ (A260) and $280 \mathrm{~nm}$ (A280) using a Nanodrop ND-1000 Spectrophotometer (Nanodrop Technologies Inc., USA). A ratio of A260/A280 $\approx 2.0$ is generally accepted as pure RNA.

cDNA synthesis

cDNA was synthesized from the RNA template using AB high capacity transcriptase kit (Applied Biosystem). Every $1 \mu \mathrm{g}$ RNA sample was reverse transcribed using $1 \mu$ l reverse transcriptase, $2 \mu \mathrm{l}$ random primer, $0.8 \mu \mathrm{l}$ dNTPs $(10 \mathrm{mM}$ each), $2 \mu$ l buffer and topped up by RNase free water to a total volume of $20 \mu \mathrm{l}$. The reaction mixture was subjected to incubation for $10 \mathrm{~min}$ at $25^{\circ} \mathrm{C}, 120 \mathrm{~min}$ at $37^{\circ} \mathrm{C}$ and $5 \mathrm{~s}$ at $85^{\circ} \mathrm{C}$.

\section{Quantitative RT-PCR (qRT-PCR)}

qRT-PCR amplification was performed using Applied Biosystems StepOnePlus Real-Time PCR System (AB International, CA). The qRT-PCR mastermix was prepared by adding $10 \mu \mathrm{l}$ AB Sybrgreen PCR mastermix (AB International, CA), $1 \mu \mathrm{l}$ reverse primer, $1 \mu$ f forward primer, $1 \mu \mathrm{l}$ cDNA and $7 \mu \mathrm{l}$ distilled water. The total volume for each real-time PCR reaction was $20 \mu \mathrm{l}$. The PCR program was set up with an initial heat activation step at $95^{\circ} \mathrm{C}$ for $10 \mathrm{~min}$. Then, 40 cycles of thermocycling were performed with a denaturation step at $95^{\circ} \mathrm{C}$ for $15 \mathrm{~s}$, an annealing step at $60^{\circ} \mathrm{C}$ for $30 \mathrm{~s}$ and an extension step at $72^{\circ} \mathrm{C}$ for $30 \mathrm{~s}$. Fluorescence was measured at the end of each extension step. After amplification, a melting curve was acquired by heating the product at $4^{\circ} \mathrm{C} / \mathrm{s}$ to $95^{\circ} \mathrm{C}$, cooling it at $4^{\circ} \mathrm{C} / \mathrm{s}$ to $70^{\circ} \mathrm{C}$, keeping it at $70^{\circ} \mathrm{C}$ for $20 \mathrm{~s}$, and then slowly heating it at $4^{\circ} \mathrm{C} / \mathrm{s}$ to $95^{\circ} \mathrm{C}$. Fluorescence was measured through the slow heating phase. Melting curves were used to determine the specificity of PCR products.

Analysis of housekeeping gene expression stability

Raw Ct values of housekeeping genes were converted to linear values compatible with the geNorm and NormFinder programs. For comparison of housekeeping gene stability between groups, the software geNorm, version 3.4 (Visual Basic application tool for Microsoft Excel) [33] was used, while for housekeeping genes stability comparison within group, NormFinder (a Microsoft Excel Add-in) [34] was used. Both programs were used according to developer's recommendations as published.

Analysis of target gene expression

Raw $\mathrm{Ct}$ values of the target gene $(\mathrm{HIF}-1 \alpha)$ were analyzed using two different methods to determine the importance of normalization to different housekeeping gene(s) in qRTPCR data analysis. 
Data analysis using $2^{-\Delta \Delta C t}$ method

Simple relative quantification of target gene expression normalized to one housekeeping gene was performed using the $2^{-\Delta \Delta \mathrm{Ct}}$ method. Derivation of the equation, including assumptions, experimental design and validation test, have been described in Applied Biosystem User Bulletin No. 2 (P/N 4303859). Analyses of gene expression data using this method have appeared in the literature [38-40].

\section{Data analysis using geNorm method}

Relative quantification of target gene expression normalized to more than one housekeeping gene was performed using the geNorm method. In this method, target gene expression was normalized to the geometric mean expression of the best combination of housekeeping genes subjected to expression stability analysis using geNorm software. Analyses of gene expression data using this method have appeared in the literature [23, 41-43].

\section{Statistical analysis}

The software program, SPSS version 18 was used for further statistical analysis of gene and protein expression among experimental groups. In all cases expression data were compared by one-way analysis of variance (ANOVA) (statistical significance $<0.05)$. The significance level $(\alpha)$ was set at 0.05 .

Acknowledgments This work was supported by the British Heart Foundation (grant number PG/07/059/23259). SCT and KKY thank the Malaysian Ministry of Higher Education for studentships.

Open Access This article is distributed under the terms of the Creative Commons Attribution Noncommercial License which permits any noncommercial use, distribution, and reproduction in any medium, provided the original author(s) and source are credited.

\section{References}

1. Beltrami AP, Barlucchi L, Torella D, Baker M, Limana F, Chimenti S, Kasahara H, Rota M, Musso E, Urbanek K, Leri A, Kajstura J, Nadal-Ginard B, Anversa P (2003) Adult cardiac stem cells are multipotent and support myocardial regeneration. Cell 114:763-776

2. Soonpaa MH, Field LJ (1998) Survey of studies examining mammalian cardiomyocyte DNA synthesis. Circ Res 83:15-26

3. Anversa P, Sussman MA, Bolli R (2004) Molecular genetic advances in cardiovascular medicine: focus on the myocyte. Circulation 109:2832-2838

4. Messina E, De Angelis L, Frati G, Morrone S, Chimenti S, Fiordaliso F, Salio M, Battaglia M, Latronico MV, Coletta M, Vivarelli E, Frati L, Cossu G, Giacomello A (2004) Isolation and expansion of adult cardiac stem cells from human and murine heart. Circ Res 95:911-921
5. Smith RR, Barile L, Cho HC, Leppo MK, Hare JM, Messina E, Giacomello A, Abraham MR, Marban E (2007) Regenerative potential of cardiosphere-derived cells expanded from percutaneous endomyocardial biopsy specimens. Circulation 115: 896-908

6. Rickers C, Gallegos R, Seethamraju RT, Wang X, Swingen C, Jayaswal A, Rahrmann EP, Kastenberg ZJ, Clarkson CE, Bianco R, O'Brian T, Verfaillie C, Bolman RM 3rd, Wilke N, JeroschHerold M (2004) Applications of magnetic resonance imaging for cardiac stem cell therapy. J Interv Cardiol 17:37-46

7. Epstein AC, Gleadle JM, McNeill LA, Hewitson KS, O'Rourke J, Mole DR, Mukherji M, Metzen E, Wilson MI, Dhanda A, Tian YM, Masson N, Hamilton DL, Jaakkola P, Barstead R, Hodgkin J, Maxwell PH, Pugh CW, Schofield CJ, Ratcliffe PJ (2001) C. elegans EGL-9 and mammalian homologs define a family of dioxygenases that regulate HIF by prolyl hydroxylation. Cell 107:43-54

8. Bruick RK, McKnight SL (2001) A conserved family of prolyl-4hydroxylases that modify HIF. Science 294:1337-1340

9. Schofield CJ, Ratcliffe PJ (2005) Signalling hypoxia by HIF hydroxylases. Biochem Biophys Res Commun 338:617-626

10. Asikainen TM, Ahmad A, Schneider BK, Ho WB, Arend M, Brenner M, Gunzler V, White CW (2005) Stimulation of HIF1alpha, HIF-2alpha, and VEGF by prolyl 4-hydroxylase inhibition in human lung endothelial and epithelial cells. Free Radic Biol Med 38:1002-1013

11. Cummins EP, Seeballuck F, Keely SJ, Mangan NE, Callanan JJ, Fallon PG, Taylor CT (2008) The hydroxylase inhibitor dimethyloxalylglycine is protective in a murine model of colitis. Gastroenterology 134:156-165

12. Tian YM, Yeoh KK, Lee MK, Eriksson T, Kessler BM, Kramer HB, Edelmann MJ, Willam C, Pugh CW, Schofield CJ, Ratcliffe PJ (2011) Differential sensitivity of HIF hydroxylation sites to hypoxia and hydroxylase inhibitors. J Biol Chem 286:1304113051

13. Lienard BM, Conejo-Garcia A, Stolze I, Loenarz C, Oldham NJ, Ratcliffe PJ, Schofield CJ (2008) Evaluation of aspirin metabolites as inhibitors of hypoxia-inducible factor hydroxylases. Chem Commun (Camb) 47:6393-6395

14. Forest L, Glade N, Demongeot J (2007) Lienard systems and potential-Hamiltonian decomposition: applications in biology. C R Biol 330:97-106

15. Orlic D, Kajstura J, Chimenti S, Jakoniuk I, Anderson SM, Li B, Pickel J, McKay R, Nadal-Ginard B, Bodine DM, Leri A, Anversa $P$ (2001) Bone marrow cells regenerate infarcted myocardium. Nature 410:701-705

16. Sun J, Li SH, Liu SM, Wu J, Weisel RD, Zhuo YF, Yau TM, Li RK, Fazel SS (2009) Improvement in cardiac function after bone marrow cell therapy is associated with an increase in myocardial inflammation. Am J Physiol Heart Circ Physiol 296:H43-H50

17. Lisi A, Ledda M, de Carlo F, Pozzi D, Messina E, Gaetani R, Chimenti I, Barile L, Giacomello A, D’Emilia E, Giuliani L, Foletti A, Patti A, Vulcano A, Grimaldi S (2008) Ion cyclotron resonance as a tool in regenerative medicine. Electromagn Biol Med 27:127-133

18. Deng A, Arndt MA, Satriano J, Singh P, Rieg T, Thomson S, Tang T, Blantz RC (2009) Renal protection in chronic kidney disease: hypoxia-inducible factor activation vs angiotensin II blockade. Am J Physiol Renal Physiol 299:F1365-F1373

19. Imperatore A, Rolfo A, Petraglia F, Challis JR, Caniggia I (2010) Hypoxia and preeclampsia: increased expression of urocortin 2 and urocortin 3. Reprod Sci 17:833-843

20. Kroening S, Neubauer E, Wessel J, Wiesener M, Goppelt-Struebe M (2009) Hypoxia interferes with connective tissue growth factor (CTGF) gene expression in human proximal tubular cell lines. Nephrol Dial Transplant 24:3319-3325 
21. Warnecke C, Griethe W, Weidemann A, Jurgensen JS, Willam C, Bachmann S, Ivashchenko Y, Wagner I, Frei U, Wiesener M, Eckardt KU (2003) Activation of the hypoxia-inducible factorpathway and stimulation of angiogenesis by application of prolyl hydroxylase inhibitors. FASEB J 17:1186-1188

22. Yang MC, Wang SS, Chou NK, Chi NH, Huang YY, Chang YL, Shieh MJ, Chung TW (2009) The cardiomyogenic differentiation of rat mesenchymal stem cells on silk fibroin-polysaccharide cardiac patches in vitro. Biomaterials 30:3757-3765

23. Wang F, Wang J, Liu D, Su Y (2010) Normalizing genes for realtime polymerase chain reaction in epithelial and non epithelial cells of mouse small intestine. Anal Biochem 399:211-217

24. Miyamoto S, Kawaguchi N, Ellison GM, Matsuoka R, Shin'oka $\mathrm{T}$, Kurosawa H (2010) Characterization of long-term cultured c-kit + cardiac stem cells derived from adult rat hearts. Stem Cells Dev 19:105-116

25. Li H, Zuo S, He Z, Yang Y, Pasha Z, Wang Y, Xu M (2010) Paracrine factors released by GATA-4 overexpressed mesenchymal stem cells increase angiogenesis and cell survival. Am J Physiol Heart Circ Physiol 299:H1772-H1781

26. Zakharova L, Mastroeni D, Mutlu N, Molina M, Goldman S, Diethrich E, Gaballa MA (2010) Transplantation of cardiac progenitor cell sheet onto infarcted heart promotes cardiogenesis and improves function. Cardiovasc Res 87:40-49

27. Zuba-Surma EK, Kucia M, Dawn B, Guo Y, Ratajczak MZ, Bolli $\mathrm{R}$ (2008) Bone marrow-derived pluripotent very small embryonic-like stem cells (VSELs) are mobilized after acute myocardial infarction. J Mol Cell Cardiol 44:865-873

28. Sluka P, O'Donnell L, Stanton PG (2002) Stage-specific expression of genes associated with rat spermatogenesis: characterization by laser-capture microdissection and real-time polymerase chain reaction. Biol Reprod 67:820-828

29. Nishimura M, Koeda A, Suzuki E, Shimizu T, Kawano Y, Nakayama M, Satoh T, Narimatsu S, Naito S (2006) Effects of prototypical drug-metabolizing enzyme inducers on mRNA expression of housekeeping genes in primary cultures of human and rat hepatocytes. Biochem Biophys Res Commun 346: 1033-1039

30. Takagi H, Shibutani M, Lee KY, Masutomi N, Fujita H, Inoue K, Mitsumori K, Hirose M (2005) Impact of maternal dietary exposure to endocrine-acting chemicals on progesterone receptor expression in micro dissected hypothalamic medial preoptic areas of rat offspring. Toxicol Appl Pharmacol 208:127-136

31. Wang X, Hsu MY, Steinbacher TE, Monticello TM, Schumacher WA (2007) Quantification of platelet composition in experimental venous thrombosis by real-time polymerase chain reaction. Thromb Res 119:593-600
32. Yuzbasioglu A, Onbasilar I, Kocaefe C, Ozguc M (2010) Assessment of housekeeping genes for use in normalization of real time PCR in skeletal muscle with chronic degenerative changes. Exp Mol Pathol 88:326-329

33. Vandesompele J, De Preter K, Pattyn F, Poppe B, Van Roy N, De Paepe A, Speleman F (2002) Accurate normalization of real-time quantitative RT-PCR data by geometric averaging of multiple internal control genes. Genome Biol 3:7

34. Andersen CL, Jensen JL, Orntoft TF (2004) Normalization of real-time quantitative reverse transcription-PCR data: a modelbased variance estimation approach to identify genes suited for normalization, applied to bladder and colon cancer data sets. Cancer Res 64:5245-5250

35. Rich BE, Steitz JA (1987) Human acidic ribosomal phosphoproteins $\mathrm{P} 0, \mathrm{P} 1$, and $\mathrm{P} 2$ : analysis of cDNA clones, in vitro synthesis, and assembly. Mol Cell Biol 7:4065-4074

36. Duan J, Nilsson L, Lambert B (2004) Structural and functional analysis of mutations at the human hypoxanthine phospho ribosyl transferase (HPRT1) locus. Hum Mutat 23:599-611

37. Kornberg RD (2007) The molecular basis of eucaryotic transcription. Cell Death Differ 14:1989-1997

38. Winer J, Jung CK, Shackel I, Williams PM (1999) Development and validation of real-time quantitative reverse transcriptasepolymerase chain reaction for monitoring gene expression in cardiac myocytes in vitro. Anal Biochem 270:41-49

39. Schmittgen TD, Zakrajsek BA (2000) Effect of experimental treatment on housekeeping gene expression: validation by realtime, quantitative RT-PCR. J Biochem Biophys Methods 46: $69-81$

40. Livak KJ, Schmittgen TD (2001) Analysis of relative gene expression data using real-time quantitative PCR and the 2(-Delta Delta C(T)) method. Methods 25:402-408

41. Kuijk EW, du Puy L, van Tol HT, Haagsman HP, Colenbrander B, Roelen BA (2007) Validation of reference genes for quantitative RT-PCR studies in porcine oocytes and preimplantation embryos. BMC Dev Biol 7:58

42. Kidd M, Nadler B, Mane S, Eick G, Malfertheiner M, Champaneria M, Pfragner R, Modlin I (2007) GeneChip, geNorm, and gastrointestinal tumors: novel reference genes for real-time PCR. Physiol Genomics 30:363-370

43. Van Zeveren AM, Visser A, Hoorens PR, Vercruysse J, Claerebout E, Geldhof P (2007) Evaluation of reference genes for quantitative real-time PCR in Ostertagia ostertagi by the coefficient of variation and geNorm approach. Mol Biochem Parasitol 153:224-227 